\title{
India y China, dos escenarios de la política internacional contemporánea
}

\section{Leonardo Mejia ${ }^{1}$ Universidad Torcuato Di Tella, Argentina}

\section{Artículo científico}

Material original autorizado para su primera publicación en el Journal de Ciencias Sociales, Revista Académica de la Facultad de Ciencias Sociales de la Universidad de Palermo.

Recibido 12-6-2017

Aceptado 10-9-2017

\section{Resumen}

La India y China son dos Estados que guardan algunas similitudes en cuanto a la búsqueda de un nuevo status político, social y económico en el mundo a partir de tres elementos importantes: la demografía, el desarrollo económico (a partir de la globalización) y los aspectos de su propia seguridad. En este sentido, el artículo presenta una recopilación de elementos para la comparación de estos dos países en procura de desarrollar un estudio más profundo acerca de cómo la China y la India han ocupado mayores espacios de acción en los ámbitos económicos y de seguridad en el Asia del este y, en general, en los nuevos entornos de la geopolítica internacional.

A partir de esto, el artículo constituye una reflexión desde una metodología que se inicia a partir de la comparación cuantitativa entre desarrollo humano y globalización, yque tiende a presentar a estos dos países como Estados orientados a ocupar espacios en la nueva estructura económica mundial. Bajo esta perspectiva, el trabajo investigativo aborda tres temas de interés para la comparación de estos dos países: el primero, centrado en la demografía y las ventajas que les brinda este aspecto frente al resto del mundo; el segundo, referente a la economía y tres líneas centrales para su análisis —el crecimiento económico, la movilidad de capital y el comercio exterior-, y por último, el tema de la seguridad, para identificar factores de interés por parte de estas dos potencias nucleares en el manejo de la seguridad regional.

El desarrollo del trabajo de investigación que aquí se presenta permitirá dar una visión general de cómo estas dos potencias de Asia del este han avanzado en distintos temas con el fin de mantener un liderazgo en la región y en procura de lograr un desarrollo interno de cada uno de sus territorios. Teniendo en cuenta esto, el trabajo se fundamenta con un marco teórico amplio que recoge teóricos clásicos de las relaciones internacionales, documentos académicos y técnicos pertinentes a esta investigación y cifras estadísticas

\footnotetext{
${ }^{1}$ Universidad Torcuato Di Tella, Argentina. Profesor en el área internacional Fundación Universitaria Juan de Castellanos www.jdc.edu.co Correo electrónico: Imejia@jdc.edu.co
} 
actualizadas provenientes de centros de estudios y organizaciones multilaterales de primer orden.

Palabras claves: China; India; Seguridad; Desarrollo y Globalización.

Abstract

India and China are two states that bear some similarities in reference to the search for a new political, social and economic status in the world from three important elements, demography, economic development (from globalization) and the issue of their own safety. In this sense, the article presents a compilation of elements for the comparison of these two countries in order to develop a deeper study on how China and India have been occupying a better place of action in the economic and security issue in the East of Asia and in general in all the new international geopolitics.

Based on this, the reflective article uses a methodology that starts from the quantitative comparison between human development and globalization, tending to present these two countries as states oriented to occupy spaces in the new global economic structure. From this perspective, the research work addresses three topics of interest for the comparative of these two countries. The first, centered on the demography and the advantages that this aspect gives to the rest of the world. The second, referring to the economy and three central lines for its analysis such as: economic growth, capital mobility and international trade. Finally, the issue of security, to identify factors of interest on the part of these two nuclear powers in the management of regional security.

The development of the research work presented here will give an overview of how these two powers of East Asia have advanced in different subjects in order to maintain a leadership in the region and in pursuit of an internal development of each one of their own territories. This paper is based on a broad theoretical framework that includes classic theorists of international affairs, academic and technical documents pertinent to this research and updated statistical figures from studies centers and multilateral organizations.

Key words: China; India; Security; Development and Globalization.

\section{Introducción}

El siguiente trabajoestá basado en una recopilación de datos referidos a dos países importantes del continente asiático: China e India. Bajo esta perspectiva, lo que se pretende desarrollar en esta investigación es un análisis de ambos países con el fin de identificar las diferencias sustanciales en lo concerniente a temas económicos, políticos y de seguridad dentro del contexto internacional de hoy en día.

En vista de que uno de los factores más importantes en el mundo contemporáneo está relacionado con el contexto de la inserción a la globalizaciónde los Estados, se presenta un análisis introductorio que tiene como objeto determinar cómo se encuentran 
China y la India en el desarrollo social, con la globalización como variable explicativa. Para esto, se toman los datos recopilados por la Universidad de Gotemburgo a través del Instituto para la Calidad de Gobierno (The Quality of Government, QOG)2017 como parte de un ejercicio metodológico cuantitativo, con el fin de presentar, de manera introductoria, la importancia de los dos países objeto del estudio en el contexto de la globalización.

Para el respectivo análisis de China y la India, se toman datos de la Organización Mundial de Comercio (OMC, 2016), del Banco Mundial y de otras fuentes calificadas y confiables, que serán fuentes básicas para el trabajo. Como primeramedida, se hará una aproximación desde una perspectiva demográfica,teniendo en cuenta que en estos dos países se concentra casi una cuarta parte de la población del planeta, lo cual ha sido un elemento clave en la política de los dos países frente al contexto internacional.

De la misma manera, los aspectos económicos y de seguridad en China y la India son analizados bajo la perspectiva de los acontecimientos contemporáneos basados en contextos enmarcados dentro de la política internacional post 9-11, que reflejan una necesidad de comprender el rol que cumplen estos dos países en el orden mundial contemporáneo. En este sentido, los textos de Kissinger (2014), Krugman (1994) y Chomsky (2016) plantean a esta región del mundo como una de las más convulsionadas en cuanto a la seguridad mundial, y a la vez como una de las zonas donde se desarrollan los procesos económicos más importantes de la actualidad.

Al finalizar el artículo, se presentarán algunas reflexiones acerca de los datos hallados, para acceder auna visión más clara de las diferencias entre la China y la India de acuerdo con los temas planteados en el trabajo. De igual forma, teniendo en cuenta que se trata de un ejercicio netamente académico, es importante plantear que no se pretende realizar una profunda investigación acerca de cada uno de los puntos diferenciadores, sino más bien, generarotro espaciopara un análisis amplio sobre estas dos potencias económicas, comerciales y nucleares desde una visión latinoamericana.

\section{China e India, apuesta por el desarrollo y la globalización}

Para el estudio de los dos países más grandes del continente asiático, es importante rescatar lo queGiovanni Arrighipresenta, al describir esta zona como una de las más importantes para el comercio y la economía del mundo. Bajo esta perspectiva, Arrighi (2005)señala cómo estos países han avanzado a partir de una tradición histórica que permitió descubrir nuevos caminos hacia una ampliación comercial y económica que los ubica en el orden internacional como dos grandes protagonistas.

Sin desconocer el papel que cumple Estados Unidos en el mundo, los dos países analizadoshan alcanzado un nivel de madurez comercial que les permite competir en el liderazgo del sistema político internacional tal como lo plantea Arrighi: 
China no sólo ha alcanzado a gran velocidad a EE. UU. en calidad del mayor socio comercial e importador de último recursoen la región del Asia Oriental, sino que también ha empezado a eclipsar a EE. UU. en la promoción de la liberalización comercial multilateral. Asimismo, en el ámbito regional,ha solicitado la integración en la ASEAN, persiguiendoal mismo tiempo conexiones económicas con Japón, Corea del sur e India. (Arrighi, 2005,p.340)

Por otro lado, en la Indiadiferentes culturas conviven de forma pacífica bajo el régimen democrático más grande del mundo. Ha logrado aprovechar los procesos de globalización a partir de la tercerización de servicios -outsourcing - los cuales se potenciaron a partir delos problemas del año $2000^{2}$, cuandograndes empresas del mundo, especialmente de los Estados Unidos, apostaronpor la conectividad india para la solución de problemas informáticos y por el servicio de postventa de muchos productos en mercados como el norteamericano (Friedman, 2013).Desde esta perspectiva, India ha salido de la tradición histórica delcolonialismo para ser un país abierto y líder de los denominados países del tercer mundo.

Teniendo en cuenta esto, China e India presentan un panorama heterogéneo e interesante en el proceso de globalización en miras de lograr un mayor desarrollo local que les permita tener un rol en el nuevo orden internacional (Kissinger, 2016) y asimismo ser más competitivos en el proceso contemporáneo. Como parte de la investigación, me parece oportuno plantear una hipótesis:aquellos países que tienen una mayor inserciónen los procesos de globalización logran un mayor desarrollo social.Desde esta perspectiva, para este primer momento del trabajo investigativo, se toman como fuente principal los datos que presenta elQuality of Government Institute (QOG) de la Universidad de Gotemburgo en Suecia, a través de su informe anual"The Quality of Government Standard Dataset" de 2017.

Sobre la base de lo planteado anteriormente, se tomó como variable dependiente el índice de desarrollo humano (IDH), creado para enfatizar que las personas y sus capacidades deberían ser el criterio final para evaluar el desarrollo de un país, no el crecimiento económico por sí solo. El IDH también puede usarse para cuestionar las opciones de políticas nacionales y preguntarse cómo dos países con el mismo nivel de Ingreso Nacional Bruto per cápita (GNI, por sus siglas en inglés)puedenpresentar diferentes resultados de desarrollo humano. Estos contrastes pueden estimular el debate sobre las prioridades de las políticas gubernamentales. El Índice de Desarrollo Humano (IDH) es una medida resumida del logro promedio en las dimensiones claves para el desarrollo humano: una vida larga y saludable, con conocimientos, y un nivel de vida decente. EI IDH es la media geométrica de los índices normalizados para cada una de las tres dimensiones. La

\footnotetext{
${ }^{2}$ Para Friedman (2013) el problema de los computadores, denominado Y2K, representó el momento crítico para la avanzada de la India como proveedor de servicios de intercomunicación y conectividad en el mundo entero.
} 
dimensión de la salud se evalúa por la esperanza de vida al nacer, la dimensión de la educación se mide por el promedio de años de escolaridad para adultos mayores de 25 años y años de escolaridad esperados para los niños de edad escolar. La dimensión del nivel de vida se mide por el ingreso nacional bruto per cápita. El IDH utiliza el logaritmo del ingreso para reflejar la disminución de su importancia con el aumento del INB (Ingreso Nacional Bruto). De la misma forma, el IDH simplifica y captura sólo una parte de lo que implica el desarrollo humano. Por último, el codebook de QOG 2017 plantea que HDRO siglas en inglés para el PNUD (Programa de las Naciones Unidas para el Desarrollo)-ofrece otros índices compuestos, como una representación más amplia de algunas de las cuestiones clave del desarrollo humano: la desigualdad, la disparidad de género y la pobreza humana (Codebook QOG, 2017,p. 565).

De la misma forma, y como variable explicativa principal, se tomó el índice de globalización,que es el promedio ponderado de las siguientes variables: globalización económica, globalización social y globalización política. Teniendo en cuenta esto, el mismo informe plantea que en el índice de globalización sele habría dado mayor peso al tema económico, seguido por la globalización social (Codebook QOG, 2017,p. 176).

Sobre la base delo anterior, habiendo considerado al índice de globalización como único efecto causal para el desarrollo humano de un Estado, se realizó un ejercicio cuantitativo a través de una regresiónbivariable que permite hacer una comprobación de la hipótesis planteada anteriormente. Para iniciar el análisis, es importante tener en cuenta que el índice de desarrollo humano varía entre 0.35 y 0.94 unidades, con una media de 0.68 unidades y una desviación estándar de 0.16. Según esta escala, Nígeres el país con el menor grado de desarrollo humano, con 0.35 unidades, y Noruega, el país con el mayor grado de desarrollo humano, con 0.94 unidades. En lo concerniente a los dos países de análisis de este trabajo, el índice de desarrollo humano para China es de 0.72 unidades y para la India es de 0.60 unidades $^{3}$.

Siguiendo con el análisis de los datos, seencontró una correlación positiva considerable de 0,80 , con lo cual se puede inferirque por cada unidad que aumente un país en el índice de globalización, este aumentará 0.0076 unidades en el índice de desarrollo humano $(\mathrm{IDH})^{4}$.De la misma forma, las variables utilizadas tienen no solamente una alta correlación, sino que son significativas. Esto se puede observar en el cuadro 1, que muestra los resultados de la regresión realizada.

Cuadro 1. Resultados de la regresión

\footnotetext{
${ }^{3}$ Para mayor claridad de los datos: Anexo 1. Datos estadísticos de cada una de las dos variables utilizadas en el ejercicio. Anexo2. Listado de los países, ordenados alfabéticamente, con sus respectivos indicadores de desarrollo humano y grado de globalización.

${ }^{4}$ Ver Anexo 3. Regresión realizada en STATA.
} 


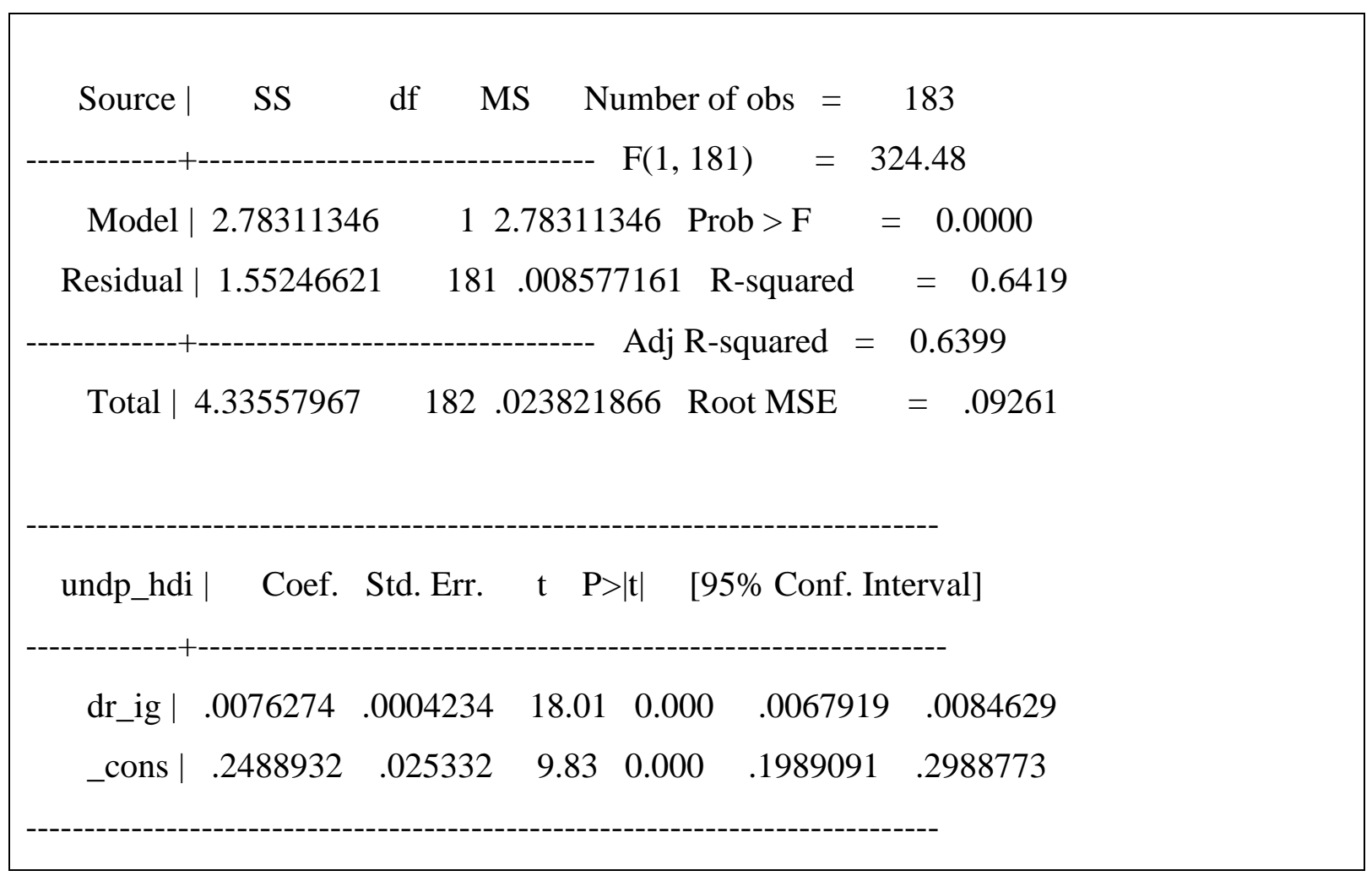

Nota: $R^{2}=0.64$ y significativo al 95\%. Para mayor información, véase el anexo 3.

En una búsqueda por darle una mayor fuerza a la explicación que permita dar respuesta a la hipótesis planteada, se realiza un gráfico de dispersión con todos los países analizados dentro de la fuente utilizada para el análisis de las variables. Esto muestra una linealidad normal que permite comprobar que a mayor nivel de globalización hay un mayor grado de desarrollo humano (véase el gráfico 1).

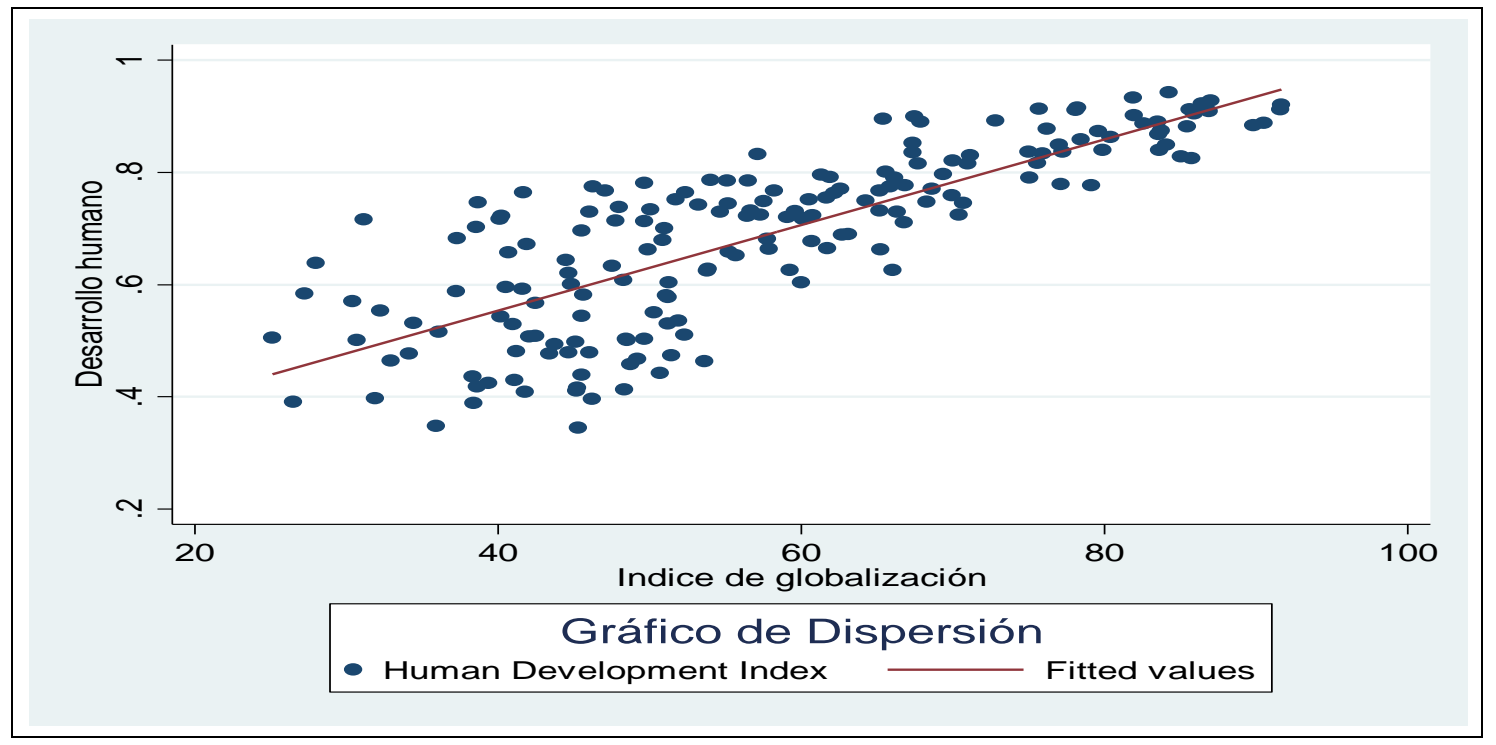


Gráfico 1. Correlación del índice de desarrollo social frente al índice general de globalización.Gráfico de dispersión y línea de regresión que muestra una correlación positiva entre estas dos variables. ${ }^{5}$

Ahora bien, teniendo en cuenta la organización metodológica que plantea el informe QOC (2017) se hace indispensable presentar la distribución geográfica utilizada por los autores, en la cual se hace una división del mundo a través de diez grandes regiones. Estas son:

Agrupación de los estados en regiones geográficas. QOC (2017)

1. Europa Oriental y la Unión Soviética (incluida Asia Central)

2. América Latina (incluyendo Cuba, Haití y la República Dominicana)

3. África del Norte y Oriente Medio (incluidos Israel, Turquía y Chipre)

4. África subsahariana

5. Europa Occidental y América del Norte (incluyendo Australia y Nueva Zelanda)

6. Asia Oriental (incluido Japón y Mongolia)

7. Asia Sudoriental

8. Asia Meridional

9. El Pacífico (excluyendo Australia y Nueva Zelanda)

10. El Caribe (incluyendo Belice, Guyana y Surinam, pero excluyendo a Cuba, Haití y la República Dominicana)

En esta clasificación la India está ubicada en la región de Asia Meridional, con países como Afganistán, Bangladesh, Bután, Sri Lanka, Maldivas, Nepal y Pakistán (1971 ). A la vez, China está ubicada como parte de la región de Asia Oriental en la cual se encuentran, además Taiwán, Japón, Corea del Norte (de la cual no se presentan datos), Corea del Sur y Mongolia. En este sentido, se presentan los datos de estas dos regiones particulares con los datos correspondientes a las variables analizadas y en donde se puede observar que China, con 9,47 unidades más en el índice de globalización, se encuentra por encima de India y asimismo tiene 0.12 unidades más que la India en cuanto a desarrollo social.

Cuadro 2. Región 8. Asia Meridional

\begin{tabular}{|l|l|l|}
\hline \multicolumn{1}{|c|}{ PAís } & Desarrollo social & Índice general de globalización \\
\hline Afganistán & .0464 & 32.9157 \\
\hline Pakistán (1971 - ) & .5358 & 51.9100 \\
\hline
\end{tabular}

\footnotetext{
${ }^{5}$ Realizado en STATA a partir de las cifras presentadas por la Universidad de Gotemburgo. (enero, 2015). Tomado de la correlación existente entre el índice de desarrollo humano y el índice de globalización. Para mayor información sobre las estadísticas respectivas véase anexo 1 y anexo 2.
} 


\begin{tabular}{|l|l|l|}
\hline Nepal & .5429 & 40.1546 \\
\hline Bangladesh & .5667 & 42.4736 \\
\hline Bután & .5951 & 40.5320 \\
\hline India & .6040 & 51.2574 \\
\hline Maldivia & .70288 & 38.5743 \\
\hline Sri Lanka & .7522 & 51.7460 \\
\hline
\end{tabular}

Fuente: QOC (2017).

\section{Cuadro 3. Región 6. Asia Oriental}

\begin{tabular}{|c|c|c|}
\hline PAÍS & $\begin{array}{c}\text { Desarrollo } \\
\text { social }\end{array}$ & $\begin{array}{c}\text { Índice } \\
\text { general de } \\
\text { globalización }\end{array}$ \\
\hline Mongolia & .7221 & 56.4258 \\
\hline China & .7233 & 60.7304 \\
\hline Japón & .8901 & 67.8583 \\
\hline $\begin{array}{l}\text { Corea } \\
\text { del Sur }\end{array}$ & .8954 & 65.4234 \\
\hline Taiwan & - & - \\
\hline $\begin{array}{l}\text { Corea } \\
\text { del Norte }\end{array}$ & - & - \\
\hline
\end{tabular}

Fuente: QOC (2017).

Sobre lo anterior, es importante destacar que el proceso de globalización de las economías ha llevado a la generación de nuevas oportunidades de desarrollo económico y social en los países que así lo encaran. Desde esta perspectiva, es de resaltar que China e India han sido partícipes de esta nueva era del proceso de globalización, en donde muchos autores como Krugman (1994), Friedman (2013)y el mismo Kissinger (2016) los consideren como los países formadores del milagro asiático. Sostienen esto no solo por el amplio crecimiento económico, sino también por lo concerniente al desarrollo de un esquema social enfocado a cambiar los viejos paradigmas de las sociedades del continente asiático a través de políticas alineadas a sistemas educativos fuertes, orientados al mejoramiento de las fuerzas productivas y competitivas hacia el contexto del mundo contemporáneo (Kissinger, 2011).

Desde esta perspectiva, en el informe anual de competitividad presentado por Lie, E., Tang, M., y Tan, K. G. (2014) se plantea cómo China, luego de treinta años de 
crecimiento económico, hace que el milagro asiático ${ }^{6}$ se vea como algo más impresionante. Chomsky (2016) presenta a China y la India como jugadores nuevos en la economía mundial, especialmente como protagonistas en el desarrollo de las fuerzas para el establecimiento de un orden internacional multipolar.

En este punto se podría afirmar que, en la competencia por conquistar los espacios del comercio internacional, tanto China como India han planteado estrategias para integrarse cada día más a las cadenas mundiales de valor y a potenciar su internacionalización a partir de procesos de cooperación e inversión en distintas partes del mundo. Para el logro de estos procesos, que se evidencia en los análisis sobre China e India, los dos países han sabido insertarse en el contexto de la globalización, lo cual les ha permitido un mejoramiento en lo concerniente al desarrollo social (medido por el IDH en esta investigación).Esto los lleva a fortalecer su presencia en el marco de la política internacional en los ámbitos económicos, políticos y de seguridad, lo que nos concierne en este trabajo.

\section{El aspecto demográfico}

Para iniciar el análisis en lo relativo a la demografía, es importante aclarar que la historia de los dos países deja una amplia diferencia en el avance tecnológico, la cosmovisión de su población y su propio desarrollo económico(Bustelo, 2007). Sin embargo, aun estas grandes brechas en sus respectivas evoluciones históricas, China y la India guardan similitudes en el contexto contemporáneo que las coloca como dos países claves en la presente política internacional.

Desde esta perspectiva, la población se convierte en el primer elemento comparativo entre estas dos naciones, tal como lo presenta Chomsky (2016) cuando manifiesta que una de las mayores fortalezas que tienen China y la India. China, con una población aproximada de 1364 millones de habitantes, sigue siendo el país más poblado del mundo, a pesar de la política del hijo único, que dejó cambios sociales que implicará sin duda transformaciones luego de que en el 2016 se levantara esta medida. Por su parte, la India, con 1267 millones de habitantes, ha aumentado su nivel demográfico, lo que le permitió mantener la presión necesaria para las transformaciones económicas y sociales enfocadas en dirigir al país hacia un proceso de mayor participación en la economía y el orden mundial.

\footnotetext{
${ }^{6}$ El milagro asiático está representado en el surgimiento de los países que hacen parte del ASEAN y de los cuales, luego de la crisis de 1997, y antes, han sabido sortear los juegos impuestos por el orden económico internacional para afianzarse como economías en vías de desarrollo con importante presencia en los mercados mundiales a partir del afianzamiento dentro de las cadenas mundiales de suministros (Supply Chain).
} 


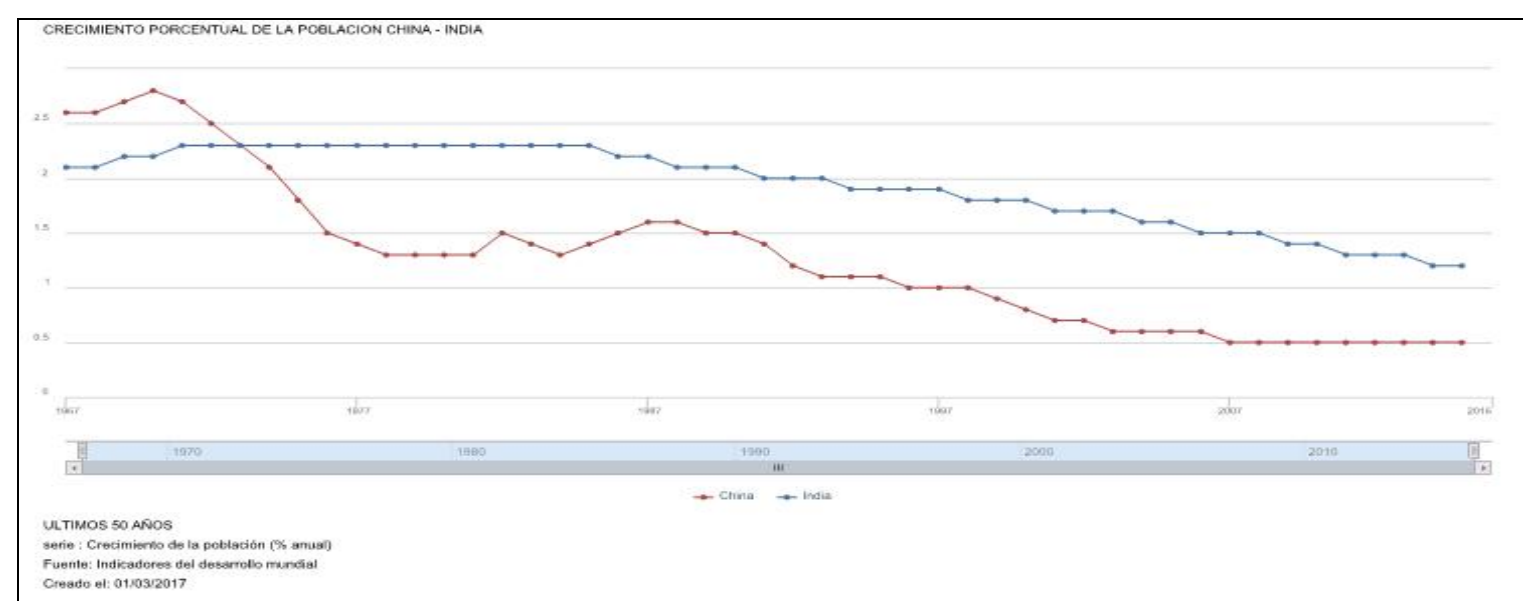

Gráfico 2. Crecimiento porcentual de la población de China e India

Como se puede observar, durante los últimos cincuenta años el crecimiento demográfico de los dos países presenta una diferencia. China, que tenía un crecimiento de $2.6 \%$ en 1967, ha llegado a un crecimiento de tan solo $0.5 \%$ en los últimos años, lo cual puede ser atribuido principalmente a la política del único hijo. En contraste, India se mantuvo con un crecimiento constante entre los años 1971 y 1985, con una tasa de crecimiento del $2.3 \%$ la cual posteriormente disminuyóhasta llegar a una tasa de $1.2 \%$ en los últimos años.

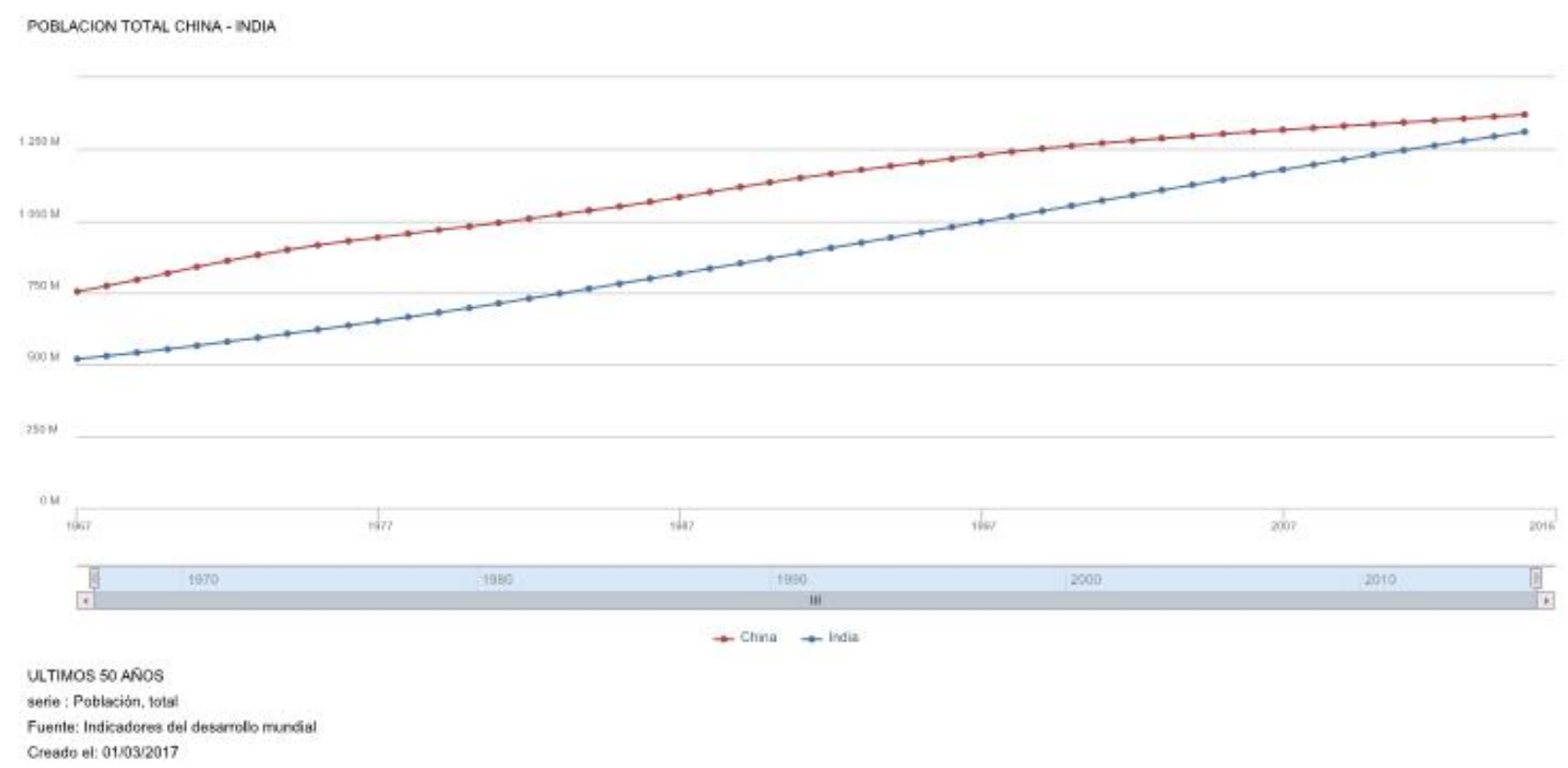

Gráfico 3. Población total de China e India

Como se puede observar en el gráfico 3, la India ha logrado alcanzar a la China en los últimos años, pero, como lo manifiesta un informe de Shreyasi Singh (2010), la India puede estar ante una bomba de tiempo por el aumento de la población y la falta de políticas estatales efectivas para el control de la natalidad y asistencia necesaria para evitar la 
dramática situación social de algunas zonas del país. Por el contrario, para China, el descenso de su población está enmarcado en la problemática de la migración interna y la concentración en las zonas urbanas. De la misma forma, como lo presentó el Partido Comunista en el año 2014, la seguridad de China está en su población, que está en un nivel peligroso de envejeciendo frente a las expectativas económicas del mundo (Den Boer y Hudson, 2014).

Siguiendo con el análisis, es importante resaltar que tanto China como la Indiason potencias en el contexto internacional, ya que su alto nivel demográfico es una fortaleza que les permite convertirse en líderes en el desarrollo económico mundial. En este sentido, es oportuno reconocer que, aunque el tema de la población en estos dos países es vital, también les plantea retos inmensos según lo presenta Chomsky (2016) al referirse a la problemática de estos dos países en competencia por el posicionamiento en el orden mundial, especialmente en lo que se refiere a la economía y a la seguridad social, como lo presentan también Maiza y Bustillo (2016).

Por otra parte, el crecimiento económico de China y su propuesta en el XIII Plan Quinquenal $^{7}$ plantean retos que ponen de manifiesto el problema demográfico. De esta forma, como lo plantean Maiza y Bustillo (2016), China tiene un desafío inmenso si quiere un mejor posicionamiento económico a partir del mejoramiento de las estructuras sociales, que le permitan un aumento en el tema demográfico escalonado y estén en línea con el plan quinquenal 2016 - 2020.

En conclusión, en los temas de población y desarrollo poblacional, China y la India tienen ventaja, pero esta ha sido mejor aprovechada por la India, en cuanto a la cantidad, mientras que China tiene que asumir unos costos muy altos para el mantenimiento de su población rural y especialmente la urbana, con subsidios para los habitantes de mayor edad y con un sistema pensional que le traerá "retos de gran complejidad y envergadura" (Maiza y Bustillo, 2016. p. 18). Ahora bien, la India por su parte, como se mostró en el gráfico 3 ha tenido un crecimiento poblacional casi a la par de China en la cantidad de habitantes, pero con una heterogeneidad cultural y social que implica retos dentro del mundo contemporáneo y que, al igual que los problemas de China en el tema demográfico, sus retos son mucho más grandes (Chomsky, 2016)debido a la heterogeneidad endógena.

\section{Economía, comercio y flujos de inversión}

\footnotetext{
${ }^{7}$ Presentado por el presidente Xi Jinping en marzo de 2016, el cual plantea la prospectiva de desarrollo de China como por ejemplo el aumento del PIB que pasará de 67,7 billones de yuanes (10,4 billones de dólares) en 2015 a más de 92,7 billones de yuanes en 2020 . Es decir, más del doble del PIB de 2010. De igual forma, plantea que ampliará sus líneas férreas de alta velocidad a 30 000 kilómetros, frente a los 19000 kilómetros actuales, con el fin de que el $80 \%$ de sus grandes ciudades estén unidas a través de esta red. Estos y otros datos pueden ser consultados en: http://en.ndrc.gov.cn/ (consultado el 17 de marzo de 2017).
} 
Es importante considerar la economía en el análisis de China y la India.. Lo que se presenta a continuación está enmarcado en tres líneas del entorno económico de los dos países. La primera de ellas está encaminada a revisar, de manera general, el comercio exterior de estas dos economías, que son protagonistas del crecimiento del comercio internacional. Posteriormente, se presentan datos de los movimientos de capitales a través de salidas y entradas de IED, con la línea transversal de lo que el profesor Baistrocchi (2016) denomina la tercera guerra financiera mundial, en la que los países se disputan los capitales mundiales.

China e India mantuvieron un crecimiento positivo durante los últimos veinte años, pero, como se puede observar en el cuadro 4, en los años 2015 y 2016, la India superó a China con un $7.6 \%$ y $7.1 \%$ del crecimiento del PIB respectivamente. Los dos países comparten a Estados Unidos y a la Unión Europea como los dos principales mercados para su comercio internacional de bienes y servicios. En el caso de la India, sus exportaciones están concentradas en los siguientes mercados: la Unión Europea, Estados Unidos, Emiratos Árabes Unidos, China yHong Kong (China). De la misma forma sus principales socios comerciales para las importaciones son: China, la Unión Europea, Arabia Saudita, Emiratos Árabes Unidos y Suiza.

China concentra sus exportaciones en los siguientes mercados: Estados Unidos, Unión Europea, Hong Kong (China), Japón y Corea del Sur. Por otro lado, sus importaciones provienen principalmente de los siguientes mercados: la Unión Europea, Corea del Sur, Japón, Estados Unidos y China (Taipéi).

\section{Crecimiento PIB (\% anual)}

\begin{tabular}{|c|c|c|c|c|}
\hline & $\mathbf{2 0 1 3}$ & $\mathbf{2 0 1 4}$ & $\mathbf{2 0 1 5}$ & $\mathbf{2 0 1 6}$ \\
\hline China & 7.8 & 7.3 & 6.9 & 6.7 \\
\hline India & 6.6 & 7.2 & 7.6 & 7.1 \\
\hline
\end{tabular}

Creado a partir de los indicadores del desarrollo

mundial serie : Crecimiento del PIB (\% anual)

Fuente: World Bank.

http://databank.worldbank.org ${ }^{8}$

Cuadro 4: Crecimiento PIB (\% anual)

\footnotetext{
${ }^{8}$ Datos estadísticos consultados en el el databank del Banco Mundial a partir de las variables de Crecimiento porcentual anual del PIB de China y la India. Realizado a través del link http://databank.worldbank.org el día 6 de septiembre de 2017.
} 
De la misma forma, con lo presentado en el informe de la Organización Mundial de Comercio (WTO, 2016)se puede analizar que la India ha diversificado su economía y ampliado su red de influencia en mercados internacionales para ejercer un mejor rol en el contexto económico internacional. Si bien es cierto que China es un país con un mayor volumen de exportaciones de mercancías $^{9}$, la India la supera en el resultado de la balanza comercial en las exportaciones de servicios comerciales, con un superávit de 33063 millones de dólares, frente a un déficit de China que llegó a a los -180854 millones de dólares para el año 2015.

De igual forma, es de resaltar que la retracción de la India ha dejado un panorama de nerviosismo en los inversionistas que le llevan a continuar ampliando los lazos comerciales con varios países del mundo, especialmente con los Estados Unidos, Japón e Israel (Dhume, 2016) con el objetivo de evitar una mayor profundización de la crisis económica. En este sentido, la India enfrenta retos económicos que dejan abierta la posibilidad de reajustar fichas claves para continuar y mantener la estructura económica que le ha permitido continuar con su crecimiento positivo de los últimos años.

El siguiente aspecto trata de los niveles de inversión extranjera y las llegadas y salidas de capital, enlas cuales, al igual que en el comercio, los dos países presentan una diferencia en los movimientos de inversión extranjera directa (IED). China ha cedido terreno frente a la India, que ha pasado de 28153 millones de dólares a 44009 millones de dólares en tan solo dos años. En este mismo sentido, China en los últimos años ha aumentado la salida, o fuga, de IED hacia distintas partes del mundo, tanto que, para el 2015 significó un $1.7 \%$ del $\mathrm{PIB}^{10}$.

Teniendo presente los flujos de la IED en el mundo, se observa que China ha ampliado la salida de capital para la realización de proyectos en distintos países de la región asiática y en otras zonas del mundo. Su finalidad fue conseguir espacios en los mercados financieros más importantes y mantener un lugar destacado dentro del orden mundial contemporáneo, afectado por la alta volatilidad de los capitales en países importantes como los que se agrupan en el G-20 (Baistrocchi, 2016). En este sentido, los corredores que se formaron para el movimiento de IED presentan al continente asiático

\footnotetext{
${ }^{9}$ De acuerdo al informe de la OMC (2016), El comercio de mercancías de China se encuentran con un superávit de 592.998 millones de dólares mientras que el de la India es deficitario en -124.830 millones de dólares para el año 2015.

${ }^{10}$ Para el caso de la IED proveniente de China, se pueden destacar los casos de Estados Unidos y la India. Para Estados Unidos, la IED de China llega a los \$134.36 billones de dólares entre los años 2005 y 2016 y para la India, la IED proveniente de China llega a \$18.96 billones de dólares para el mismo periodo. Fuente: http://www.aei.org/china-global-investment-tracker/ consultado el 4 de enero de 2017.
} 
como uno de los de mayor recepción de capitales de inversión, lo que le permite mantener su lugar en la competencia del mercado financiero internacional.

IED entrada neta de capital ${ }^{11}$

\begin{tabular}{|l|r|r|r|}
\hline & \multicolumn{1}{|c|}{2013} & \multicolumn{1}{|c|}{2014} & \multicolumn{1}{c|}{2015} \\
\hline China & 290928.431467 & 268097181064 & 249858920110 \\
\hline India & 28153031.270 & 34576643694 & 44009492129 \\
\hline
\end{tabular}

Creado a partir de indicadores del desarrollo mundialserie : Inversión extranjera directa, entrada neta de capital (balanza de pagos, US\$ a precios actuales)

Cuadro 5: IED entrada neta de Capital China - India

Fuente: Banco Mundial, 2016

Habría que decir también que China ha avanzado en la estructuración de corredores entre Asia Meridional y Asia Sudoriental: el Corredor Económico Bangladesh-China-IndiaMyanmar y el Corredor Económico China-Pakistán (UNCTAD, 2014). En contraste, la India ha apostado a acuerdos como lo es el ASEAN y específicamente al acuerdo RCEP (Regional Comprehensive Economic Partnership), que le ha permitido participar más activamente en proyectos de inversión en países de bajos ingresos. Desde esta perspectiva, se puede visualizar la diversificación de la economía india y su amplitud, que fortalecen su papel en el contexto de la política internacional.

Todas estas observaciones -sobre el desarrollo económico, el comercio internacional, los flujos de capitales de IED y otros aspectos económicos de estos paísesestán orientadas a lograr un rol más protagónico por parte de China y la India en el contexto del continente asiático y del mundo en general. Bajo esta perspectiva, es interesante el esquema creado a partir de la puesta en marcha del Banco de Desarrollo Asiático (ADB Asian Development Bank por sus siglas en inglés), que ha logrado un nuevo espacio para la generación de procesos de desarrollo en distintas partes del continente asiático y en otras partes del mundo, especialmente en África, Asia central y la Europa de los países PECO (Países de la Europa Centro Oriental).

Inversión extranjera directa, salida neta de capital

\footnotetext{
${ }^{11}$ Los valores se presentan hasta el 2015 debido a que para el año 2016 solamente se reporta el valor de China que llega a los 170556525 dólares. La India en el año 2016, no presenta datos para el ejercicio desarrollado en http://databank.bancomundial.org en las variables analizadas: Inversión extranjera directa, entrada neta de capital e Inversión extranjera directa salida neta de capital; año 2012 a 2016.
} 


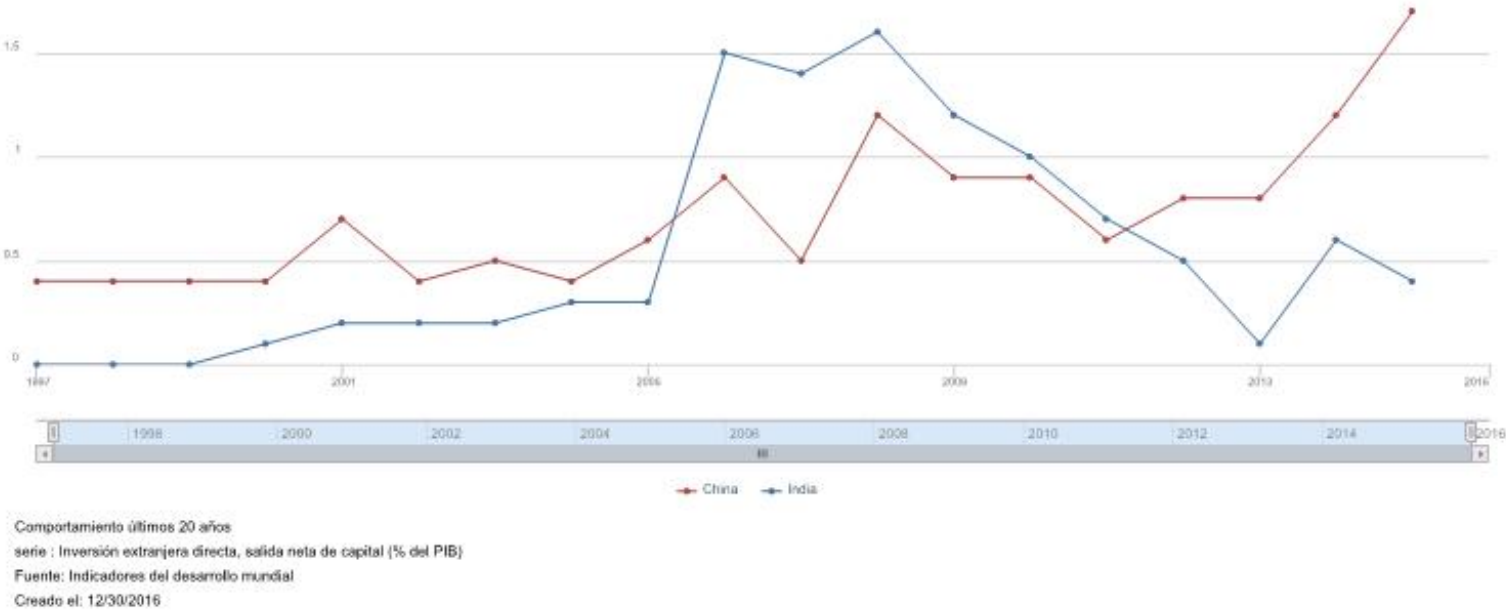

Gráfico 4: IED salida neta de capital China - India

Con respecto a esto, la iniciativa china OBOR (One Belt, One Road), ha llevado a China a plantear esquemas de cooperación a partir del nuevo marco de infraestructura, en el que países como Laos, Myanmar, Vietnam, Tailandia y Camboya, han adelantado proyectos de mejoramiento de obras de infraestructura que permitan la conexión con esa nueva ruta de la seda, que intenta unir el comercio asiático a partir del corredores comerciales enfocados en hacerse parte de las cadenas mundiales de comercio (Soong, 2016). En contraste con datos del mismo ADB, se puede encontrar que la India está centrada en el crecimiento interno. Su economía, como se mencionó anteriormente, creció a un ritmo del $7.4 \%^{12}$ anual en promedio durante los últimos tres años y espera lograr una ampliación de su influencia internacional como lo visualizaba Nehru, que planteabauna India orientada al control de la zona del Asia del Este y en lineamiento a los países en vía de desarrollo (Nissan, 2009) ${ }^{13}$.India se aisló de occidente y tomó una línea más prosoviética durante la Guerra Fría.

\section{Seguridad y defensa}

Como parte del trabajo de esta investigación, se considera la seguridad y defensa.Es necesario comenzar recordando que una de las problemáticas de la zona del

\footnotetext{
${ }^{12}$ Tomado de Asian Development Outlook 2017: Growth Outlook. en: https://www.adb.org/ (consultado el 8 de agosto de 2017).

${ }^{13} \mathrm{Al}$ igual que China, con el desarrollo del plan de OBOR, la India ha desarrollado procesos de cooperación con países vecinos con el fin, tal como lo presenta Sanjay Chaturvedi (Nissan, 2009. P23) "Within such a framework, the littoral states of Southern Asia could cooperate with one another in areas such as exploitation of living and non-living maritime resources, development of maritime communications, shipbuilding, weather forecasting, prevention of pollution, combating maritime terrorism and energy security."Esto, si se compara con los programas de cooperación de China, son parte de los esquemas de tensiones comerciales que se presentan entre estos dos países y que afectan el orden internacional.
} 
Asia Meridional y del Este es lo concerniente a las disputas territoriales que aún se mantienen vigentes, como el problema de Cachemira entre la India y Pakistán, y las islas Senkaku en Japón y Diaoyu en China. Sin embargo, en este artículo lo que se destaca es los presupuestos de defensa de los dos países analizados, lo que deja un espacio amplio para visualizar más profundamente las problemáticas particulares, tanto de China como de la India en otros trabajos.

Como primera medida se puede decir que las disputas comerciales y económicas de la zona del Asia del Este han trasladado la atención hacia los temas militares, ya que se emprendió una lucha por el control de espacios vitales y corredores de comercio. Tanto China como India, países poseedores de armamento nuclear, requieren de un alto presupuesto para un desarrollo tecnológico que les permita mantenerse en la disuasión del sistema internacional.

Como lo manifiestan distintos informes, la percepción de inseguridad en la región es cada vez más alta, por lo cual las iniciativas de China y la India están llevando sus miedos a la internacionalización a partir de la entrada en vigor de distintas alianzas en procura de mantener una postura realista y lograr así el equilibrio de poder en la región. Desde esta perspectiva, Mohan Malik (2016)presenta un análisis de las diferencias entre la China y la India a partir de la necesidad de mantener el control geopolítico de la zona surasiática y junto con Chaturvedi (2009), Friedman (2012) y Kissinger (2016)muestran a Asia como una zona de disputas geoestratégicas que enmarcan el nuevo rumbo de la política internacional contemporánea.

En el tema de seguridad hay que sumar además el rol que cumple Estados Unidos en el área de influencia de India y China. Considerando que las políticas exteriores de los países son diversas y pueden estar ajustadas a tradicionales estrategias de seguridad por parte de los Estados como China, Japón, Corea de Sur, Corea del Norte ${ }^{14}$ y la India, Estados Unidos cumple un papel importante en el establecimiento del orden en la zona a partir de la demostración de su poderío para mantener el tradicional equilibrio de poder. En este sentido, Chomsky (2016) resalta el rol preponderante del poderío americano frente a los sistemas de seguridad chinos en el área. Según la posición y la visualización de los mismos, serían considerados esquemas "defensivos" o "amenazantes", lo que trae de por sí complejidades en la seguridad de los mares de China, lo que repercute en toda la zona del Asia del Este.

\footnotetext{
${ }^{14}$ Chomsky (2016) no menciona el caso de Corea del Norte exactamente como parte del juego del equilibrio de poder que está desarrollándose en los entornos de los mares de China, pero, al considerar las pruebas armamentistas y las demostraciones de poder que ha llevado a cabo en los últimos años el gobierno de Pyongyang, que han sido vistas como una amenaza, con la llegada de Trump en 2017, altera el panorama en esta zona particular y del mundo en general.
} 
Los países del Asia del Este buscan mantener un canal de comunicación con China y no perder las líneas comerciales que este país ofrece, pero a la vez Washington, Tokio, Canberra y Nueva Delhi comparten el interés común de asegurar que la región del IndoPacífico no esté dominada por China y que el balance de poder permanezca favorable a las democracias liberales, a través del Quadrilateral Security Dialogue (QUAD) (Malik, 2016).Se debe agregar que tanto China como la India, en su carrera expansionista de desarrollo de rutas comerciales para ampliar su rol en la economía mundial, han avanzado en procesos como los proyectos de cooperación a través de espacios geográficos cercanos.

Como se puede observar en el gráfico 5 , realizado por el Instituto Internacional de Estudios Estratégicos (IISS, 2015), el país con mayor presupuesto de defensa es Estados Unidos con 597.5 billones de dólares, seguido por China con 145.8 billones. En sexto lugar se encuentra la India con 48 billones de dólares, por encima de Francia, Japón, Alemania y Corea del Sur. La diferencia entre el primer presupuesto y el segundo es extremadamente alta. China aventaja a la India en casi 100 billones de dólares anuales, lo cual pone de manifiesto la necesidad de la India de romper su tradicional no alineamiento y establecer acuerdos con países como Estados Unidos y Japón, para de mantener un equilibrio de poder frente a las prospectivas inversiones chinasen materia de seguridad militar y reforzar el proceso del QUAD.

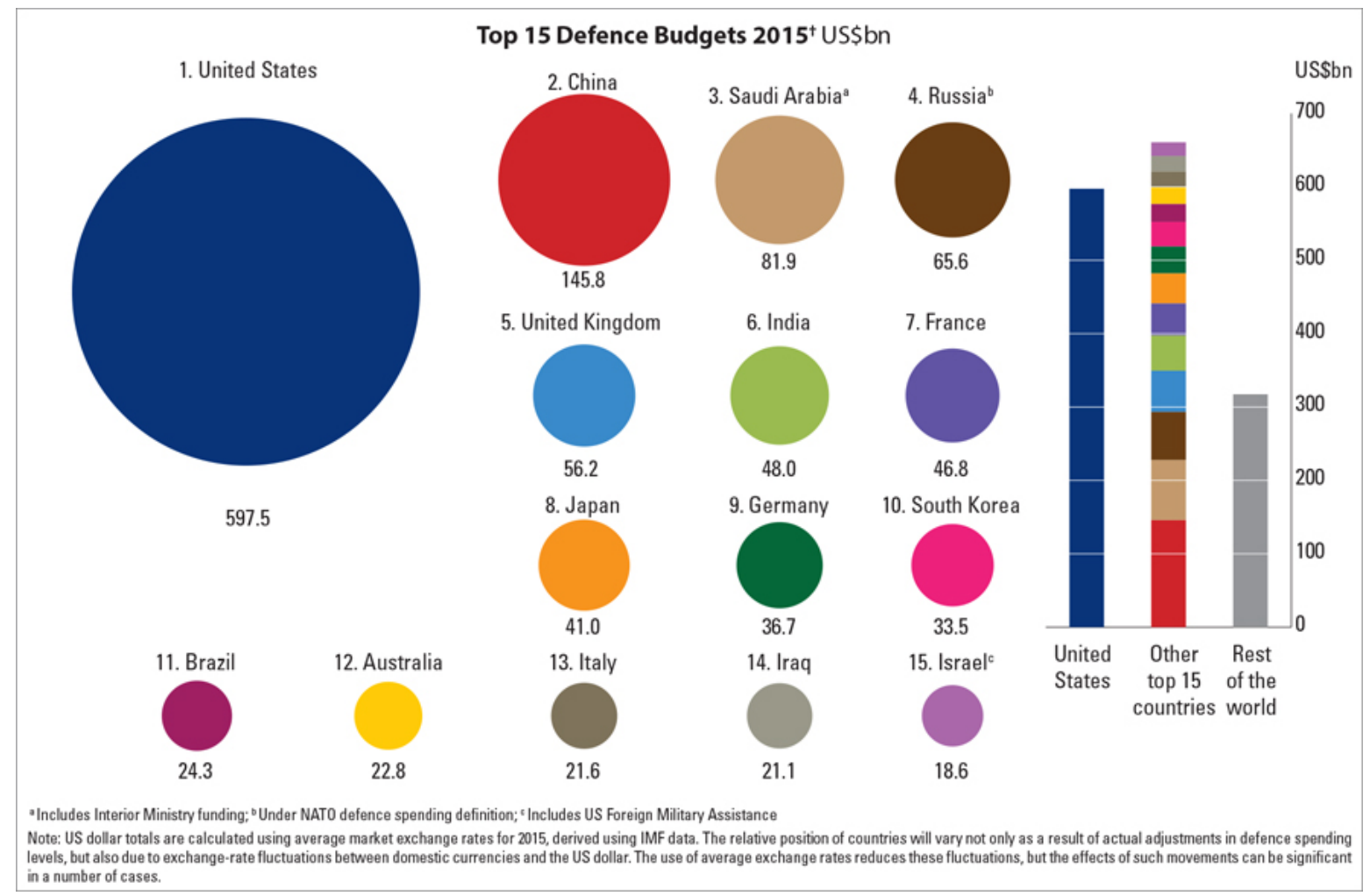

Gráfico 5: Presupuesto en defensa 2015. IISS. Fuente: Rajendran, 2016. 
Siguiendo esta perspectiva, para el año 2025 se espera que China tenga un aumento en la fuerza militar, ya que contaría para esa fecha con cuatro portaviones y con el aumento de su fuerza submarina (de capacidad nuclear). Busca la manera de contrarrestar con eficacia a los competidores regionales como Japón y la India en el control de las rutas comerciales que conectan con Euroasia (Malik, 2016). De la misma forma, el presidente chino Xi Jinping planteó en el decimotercer plan quinquenal la propuesta "One Belt One Road", tal como se explicó anteriormente, que consiste en asegurar la zona de Euroasia y así mantener el control de los recursos materiales necesarios para el desarrollo económico del país. De la misma forma, cabe recordar que se estima que el comercio en el mar del sur de China alcanza los 5.3 trillones de dólares, por lo cual el escenario geopolítico contemporáneo se desplaza indiscutiblemente a esa zona del mundo (Malik, 2016).

Para finalizar, es vital considerar el rol de Estados Unidos para el mantenimiento del orden en esta zona, debido al alto flujo de IED y de transacciones comerciales que se mueven desde el Asia del Este hacia América y Europa. Como China y la India concentran gran parte del capital de los negocios de Estados Unidos, este país es clave para el aumento de las diferencias entre ellas, en los aspectos comerciales y militares. En este sentido, la India también ha iniciado una carrera armamentista, que la lleva a adquirir tecnología militar rusay americana, y a integrarse en alianzas como las establecidas bajo el amparo de la ASEAN, a través de la alianza QUAD con Estados Unidos, Japón y Australia (Malik, 2016).

\section{Conclusiones}

Con los datos presentados, hallamos que la correlación entre la globalización y el nivel de desarrollo humano de los países es altamente positiva y por lo tanto inferir, sin llegar a determinar efectos causales, que tanto China como la India constituyen dos ejemplos claros de economías abiertas orientadas aumentar su grado de desarrollo económico para reducir las brechas sociales que existen desde tiempos históricamente proteccionistas. A partir de esto, se evidencian tres elementos claves en el proceso de análisis entre China y la India, que pueden determinar el futuro de la geopolítica mundial. Son la demografía, la economía, y la seguridad y defensa.

Desde esta perspectiva, se presenta un análisis académico en que se evidencia que el crecimiento económico de estos dos países ha sido positivo y se muestra una línea de crecimiento para los próximos años. Uno de los temas importantes para la seguridad económica, en China particularmente, es el de recuperar un nivel adecuado de población, pues el envejecimiento ocasionado por la política de un solo hijo, podría llevar a varias situaciones problemáticas, como los costos elevados de las pensiones a futuro, una fuerte 
presión poblacional en las zonas urbanas y a un éxodo desde las regiones rurales, necesarias para las proyecciones económicas de China en el futuro cercano.

En esta misma línea, la India ha aumentado en población y casi alcanza a la China en el número de habitantes. Rompió una tradición aislacionista de política de NOAL, y se orientó a las transformaciones tecnológicas necesarias para su crecimiento y desarrollo. Lo que la India logró en los últimos años fue la tercerización de servicios tecnológicos para grandes empresas internacionales, lo que le permitió ser competitiva a nivel global.

Por el gran crecimiento económico, el nivel de población y la necesidad de controlar lar las zonas del sur y el este de Asia, las rutas comerciales más importantes del mundo, se vuelven motivo de grandes disputas a partir del manejo de esos corredores de comercio que permiten tener acceso a los recursos naturales provenientes de Eurasia, África y el Medio Oriente, que son vitales para mantener el nivel de crecimiento y desarrollo económico. En este sentido, el problema de la seguridad de la región se ha convertido en un elemento indispensable para estos dos países, por lo que se han hecho inversiones en temas de seguridad y defensa, para mantener un equilibrio de poder, pero siempre con la participación de Estados Unidos, pendiente de asegurar las inversiones y los capitales en esta zona del mundo.

Para terminar, lo que se destaca en el trabajo es que China y la India son dos economías importantes en el proceso de globalización, ya que han logrado mantener un crecimiento económico importante a través del desarrollo de procesos de internacionalización, pero con un alto costo social en la solución de problemas internos. Esto se evidencia a partir de los resultados hallados en el desarrollo de la investigación, según los cuales los dos países mantienen un nivel medio de internacionalización, medida a partir del índice de globalización utilizado en el ejercicio de regresión, aunque su desarrollo humano no mantiene una línea igual de crecimiento.

En este aspecto, es interesante resaltar cómo a partir de este ejercicio se podría inferir que aunque los dos países tienen una ventaja demográfica frente al mundo, su escaso desarrollo humano les llevará a atrasar su idea de lograr un mejor posicionamiento en la política internacional. Con el fin de visualizar esto de una manera más clara, se puede afirmar que China e India, que mantienen un nivel medio en el índice de globalización y tienen una gran importancia económica en el mundo contemporáneo, poseen un nivel de desarrollo humano (social) relativamente bajo, de tan solo 0.72 para China y de 0.60 para la India. Esto llevaría a inferir que, pese a esa ventaja competitiva, que de hecho tienen estas dos economías, se enfrentan a retos muy grandes para lograr una equidad interna y un desarrollo social adecuado para avanzar en sus proyectos del complejo sistema internacional. 
Sin desconocer el hecho de que estas dos economías ocupan un papel protagónico en los contextos económicos internacionales, tienen disputas en el mantenimiento de la competitividad, originadas en la necesidad de captar recursos de IED. Es interesante analizar cómo los proyectos de cada uno de estos dos países, como por ejemplo el OBOR por parte de China y las alianzas con ASEAN y RCEP por parte de la India, muestran una dinámica que encierra asuntos, no solamente económicos, sino también esquemas de seguridad. En este último aspecto, el papel que juega Estados Unidos en esta zona del Asia del Este es trascendental por la protección de los capitales de IED de esta región. 


\section{Índice de gráficos y tablas}

\section{Gráficos}

Gráfico 1. Gráfico de dispersión del índice de desarrollo humano frente al índice de globalización.

Gráfico 2. Crecimiento porcentual de la población de China e India.

Gráfico 3. Población total de China e India.

Gráfico 4: IED salida neta de capital de China e India.

Gráfico 5: Presupuesto de defensa 2015. IISS.

\section{Cuadros}

Cuadro 1.Resultado del ejercicio de regresión entre el índice de desarrollo humano y el índice de globalización.

Cuadro 2.Listado de países de la región 8. Asia Meridional de acuerdo con el codebook de QOC (2017)

Cuadro 3. Listado de países de la región 6. Asia Oriental de acuerdo con el codebook de QOC (2017)

Cuadro 4.Crecimiento del PIB (\% anual)

Cuadro 5.IED entrada neta de capital en China e India

Anexos

Anexo 1. Datos estadísticos de las variables

Anexo 2. Listado de los países y sus respectivos resultados.

Anexo 3. Regresión 
Anexo 1

Datos estadísticos de las variables índice de globalización e índice de desarrollo humano. Tomados de STATA utilizando las cifras del QOC (2017)

\begin{tabular}{|c|c|c|}
\hline Variable | & Mean Std. Dev. & Min $\quad$ Max \\
\hline Indice de desarrollo hu & mano (Variable depen & diente) \\
\hline | $\quad 186 \quad .6890141$ & . 1552547 .3446366 & .942322 \\
\hline Variable | & Std. Dev. & Max \\
\hline Indice de globalizació & (Variable Independie & nte) \\
\hline 57.59918 & $16.21256 \quad 25.09796$ & 91.69517 \\
\hline
\end{tabular}

Cifrado en el codebook como:

Indice de desarrollo humano. undp_hdi

Indice de globalización. dr_ig 


\section{Anexo 2}

Listado de países con sus respectivos resultados de acuerdo a las variables. Se han resaltado China e India por ser los países objeto del estudio.

\begin{tabular}{|c|c|}
\hline & País undp_hdi dr_ig | \\
\hline 1. & Afghanistan .46392292 $32.915791 \mid$ \\
\hline 2. 1 & Albania $\quad .7322455 \quad 56.676414 \mid$ \\
\hline 3. 1 & Algeria . .73362184 50.057373 | \\
\hline 4. 1 & Andorra $.84350473 \quad$. \\
\hline 5.1 & Angola $.52967924 \quad 40.993053$ \\
\hline 6.1 & Antigua and Barbuda .7813733249 .649673 | \\
\hline 7.1 & Argentina $.83277309 \quad 57.11438 \mid$ \\
\hline 8. 1 & Armenia $.73091888 \quad 59.621998 \mid$ \\
\hline 9.1 & Australia .93338919 81.930656| \\
\hline $10 . \mid$ & Austria .8842336589 .829292 \\
\hline 11. & Azerbaijan . $74891788 \quad 57.530556$ | \\
\hline 12. $\mid$ & Bahamas .78601032 $54.051685 \mid$ \\
\hline 13. & Bahrain .82132775 69.989433| \\
\hline 14. & Bangladesh .56671011 42.47361| \\
\hline $15 . \mid$ & Barbados . .78514498 56.495392 | \\
\hline 16. & Belarus .79608935 $61.338795 \mid$ \\
\hline 17. & Belgium .88811749 90.509827| \\
\hline 18. $\mid$ & Belize .71450526 47.738731| \\
\hline 19. $\mid$ & Benin .47737598 43.372467| \\
\hline 20.1 & Bhutan .59508389 $40.532066 \mid$ \\
\hline 21. & Bolivia .65802908 55.253868| \\
\hline 22. 1 & Bosnia and Herzegovina $\quad$.7293008 66.313835 | \\
\hline 23. $\mid$ & Botswana $.69568992 \quad 45.517139 \mid$ \\
\hline 24. $\mid$ & Brazil .75150114 60.503361| \\
\hline $25 . \mid$ & Brunei .85247999 67.382401| \\
\hline
\end{tabular}




\begin{tabular}{|c|c|}
\hline & -----------------------------------------------------------| \\
\hline 26. $\mid$ & Bulgaria $.77923781 \quad 77.157372$ | \\
\hline $27 . \mid$ & Burkina Faso .3961616546 .203362 | \\
\hline 28. $\mid$ & Burundi $.39747557 \quad 31.869862 \mid$ \\
\hline 29. $\mid$ & Cambodia .5502450550 .317955 | \\
\hline 30. $\mid$ & Cameroon $\quad .5069896 \quad 42.055725 \mid$ \\
\hline 31. $\mid$ & Canada $.91202867 \quad 85.67292$ \\
\hline 32. $\mid$ & Cape Verde .64337069 44.476803 | \\
\hline 33. $\mid$ & Central African Republic .34768468 35.903831 | \\
\hline 34. $\mid$ & Chad .38848913 $38.418724 \mid$ \\
\hline 35. $\mid$ & Chile .83001775 $71.178299 \mid$ \\
\hline 36. $\mid$ & China $\quad .72330785 \quad 60.730404 \mid$ \\
\hline 37. 1 & Colombia .71791995 60.271091| \\
\hline 38. $\mid$ & Comoros $\quad .5012503930 .713219 \mid$ \\
\hline 39. $\mid$ & Congo .58180785 45.664997| \\
\hline 40. 1 & Congo, Democratic Republic .42957154 41.117119| \\
\hline 41. $\mid$ & $\begin{array}{lll}\text { Costa Rica } & .7637893 \quad 62.186073 \mid\end{array}$ \\
\hline 42. $\mid$ & Cote d'Ivoire $.45796213 \quad 48.755646 \mid$ \\
\hline 43. $\mid$ & Croatia $.8171461275 .593231 \mid$ \\
\hline 44. $\mid$ & Cuba .76792556 $47.088203 \mid$ \\
\hline 45. 1 & Cyprus (1975-) \\
\hline 46. $\mid$ & Czech Republic .86805749 83.598396| \\
\hline 47. 1 & Denmark .92280936 86.441978| \\
\hline 48. $\mid$ & Djibouti .46759546 49.201321 | \\
\hline 49. 1 & Dominica .7225120140 .250515 | \\
\hline 50. $\mid$ & Dominican Republic . 7107331866.807983 | \\
\hline 51. & Ecuador .72970647 54.661304 | \\
\hline 52. $\mid$ & Egypt $.6887024 \quad 62.71085$ | \\
\hline 53. $\mid$ & El Salvador .66427469 61.723335 | \\
\hline
\end{tabular}




\begin{tabular}{|c|c|}
\hline 54. $\mid$ & Equatorial Guinea .5842333427 .221102 | \\
\hline 55. $\mid$ & Eritrea $.3904867526 .473171 \mid$ \\
\hline 56. $\mid$ & Estonia $\quad .85861772 \quad 78.46434 \mid$ \\
\hline 57. 1 & Ethiopia (1993-) . .43596992 38.324123 | \\
\hline 58. $\mid$ & Fiji $\quad .7244477957 .334141 \mid$ \\
\hline 59. $\mid$ & Finland .88203788 85.466995 | \\
\hline $60 . \mid$ & France (1963-) $\quad .88702631 \quad 82.611839 \mid$ \\
\hline 61. $\mid$ & Gabon .67895639 50.876392 | \\
\hline 62. $\mid$ & Gambia $.44173524 \quad 50.679447$ | \\
\hline 63. $\mid$ & Georgia .75011814 64.265739| \\
\hline 64. $\mid$ & Germany $.91516227 \quad 78.24411 \mid$ \\
\hline 65. $\mid$ & Ghana .5770778151 .229294 | \\
\hline 66. $\mid$ & Greece $\quad .8634268 \quad 80.401207 \mid$ \\
\hline $67 . \mid$ & Grenada $.7417696153 .207664 \mid$ \\
\hline 68. $\mid$ & Guatemala .62615323 59.278511 | \\
\hline 69. $\mid$ & Guinea .41092396 45.194004 | \\
\hline 70.1 & Guinea-Bissau . $.4183560938 .619301 \mid$ \\
\hline 71. 1 & Guyana $.63360715 \quad 47.50692$ | \\
\hline $72 . \mid$ & Haiti $\quad .4813084 \quad 41.214916 \mid$ \\
\hline 73. 1 & Honduras $\quad .6042573559 .988316$ | \\
\hline 74. 1 & Hungary $\quad .82537055 \quad 85.7771 \mid$ \\
\hline 75. 1 & Iceland .89939946 67.497147 | \\
\hline $76 . \mid$ & India .6039782251 .257374 \\
\hline 77.1 & Indonesia .6810551357 .754116 \\
\hline 78. $\mid$ & Iran .76413763 $41.654881 \mid$ \\
\hline 79. 1 & Iraq $.65699941 \quad 40.703957 \mid$ \\
\hline 80. 1 & Ireland .91230631 91.644218| \\
\hline 81. $\mid$ & Israel $\quad .89257997 \quad 72.812981 \mid$ \\
\hline
\end{tabular}




\begin{tabular}{|c|c|}
\hline 82. $\mid$ & Italy $.87318897 \quad 79.589424$ \\
\hline 83. 1 & Jamaica $\quad .71738726 \quad 60.111988$ \\
\hline 84. $\mid$ & $\begin{array}{lll}\text { Japan } & .89009637 & 67.858315\end{array}$ \\
\hline 85. $\mid$ & Jordan $.74751806 \quad 68.314888$ \\
\hline 86. $\mid$ & Kazakhstan .78504139 55.097397| \\
\hline 87. 1 & Kenya .5443494945 .510342 | \\
\hline 88. $\mid$ & Kiribati $\quad .5884909 \quad 37.269398$ \\
\hline 89. $\mid$ & Korea, North $\quad$. $\quad . \mid$ \\
\hline $90 . \mid$ & Korea, South .89538395 65.423386 | \\
\hline 91. & Kuwait .81577128 67.687386 | \\
\hline $92 . \mid$ & Kyrgyzstan .65207726 55.68792 \\
\hline 93. $\mid$ & Laos $.56990159 \quad 30.37561 \mid$ \\
\hline 94. $\mid$ & Latvia $\quad .81575608$ 70.969215 | \\
\hline 95. $\mid$ & Lebanon .76754433 65.182167| \\
\hline 96. $\mid$ & Lesotho .4938955 43.739494| \\
\hline $97 . \mid$ & Liberia $\quad .42428541 \quad 39.393604 \mid$ \\
\hline 98. & Libya .73787838 $47.979198 \mid$ \\
\hline 99.1 & Liechtenstein .90699673 . \\
\hline 100. & Lithuania $.83713406 \quad 77.255585$ | \\
\hline 101. & Luxembourg $.8900701483 .551834 \mid$ \\
\hline 102. & Macedonia .74447525 55.162453 | \\
\hline 103. & Madagascar .50825793 42.465912 | \\
\hline 104. & Malawi $.43877354 \quad 45.54771 \mid$ \\
\hline 105. & Malaysia (1966-) . \\
\hline 106. & Maldives .70288289 38.574348 | \\
\hline 107. & Mali .41580108 45.230202 | \\
\hline 108. & Malta .83704478 75.038467| \\
\hline 109. & Marshall Islands $\quad \cdot \quad \cdot$. \\
\hline 110. & Mauritania .50353724 48.478149| \\
\hline
\end{tabular}




\begin{tabular}{|c|c|}
\hline $\mid---\cdot$ & ------------------------------------------------| \\
\hline 111. & Mauritius .7746975465 .879883 | \\
\hline 112. & $\begin{array}{lll}\text { Mexico } & .7547186 & 61.652943\end{array}$ \\
\hline 113. & Micronesia $\quad .63870037 \quad 27.994192$ | \\
\hline 114. | & Moldova .68980014 63.139164| \\
\hline $115 . \mid$ & Monaco \\
\hline 116. $\mid$ & Mongolia .72214758 56.425758| \\
\hline 117. | & Montenegro .80086088 $65.572121 \mid$ \\
\hline 118. & Morocco $.62625223 \quad 66.06118 \mid$ \\
\hline 119. & Mozambique .41254869 48.360573| \\
\hline $120 . \mid$ & Myanmar $.53136355 \quad 34.424519$ | \\
\hline 121. & Namibia .6251941353 .784672 | \\
\hline 122. $\mid$ & Nauru $\quad . \quad . \mid$ \\
\hline 123. | & Nepal .54290944 $40.154606 \mid$ \\
\hline 124. & Netherlands .9204423491 .695168 \\
\hline 125. $\mid$ & New Zealand .9113158678 .145599 | \\
\hline 126. & Nicaragua .62839067 $53.882164 \mid$ \\
\hline 127. & Niger .34463659 $45.27887 \mid$ \\
\hline 128. & Nigeria $.5104914952 .317375 \mid$ \\
\hline 129. & Norway .94232196 84.244888 | \\
\hline 130. & Oman .79158723 61.913265| \\
\hline 131. & Pakistan (1971-) $\quad$.53579676 51.910027 | \\
\hline 132. & Palau .77515149 $46.285927 \mid$ \\
\hline 133. & $\begin{array}{lll}\text { Panama } & .77657717 & 66.87484\end{array}$ \\
\hline 134. $\mid$ & Papua New Guinea $\quad .50278044 \quad 49.661819$ | \\
\hline 135. & Paraguay .67692608 60.693493 | \\
\hline 136. $\mid$ & Peru . .73192298 65.201851| \\
\hline 137. & Philippines .66352654 57.861015 | \\
\hline 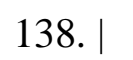 & Poland .83992612 79.895012 | \\
\hline
\end{tabular}




\begin{tabular}{|c|c|}
\hline 139. $\mid$ & Portugal .82807457 $85.078094 \mid$ \\
\hline $140 . \mid$ & Qatar .84879386 77.042305 | \\
\hline 141. & Romania $\quad .790759575 .089333$ | \\
\hline 142. $\mid$ & $\begin{array}{lll}\text { Russia } & .7973693 \quad 69.40332 \mid\end{array}$ \\
\hline 143. | & Rwanda $\quad .478596 \quad 44.664104 \mid$ \\
\hline $144 . \mid$ & Samoa .70052773 50.961731| \\
\hline 145. $\mid$ & San Marino $\quad \cdot \quad \cdot \quad \cdot \mid$ \\
\hline 146. $\mid$ & Sao Tome and Principe $\quad .5533090232 .245296$ | \\
\hline 147. & Saudi Arabia .83555448 67.346481 | \\
\hline 148. $\mid$ & Senegal .46317846 53.612999 | \\
\hline 149. $\mid$ & Serbia $.7709205768 .619438 \mid$ \\
\hline $150 . \mid$ & Seychelles $\quad .76746505 \quad 58.237488$ \\
\hline 151. & Sierra Leone .40824994 41.769115 | \\
\hline 152. | & Singapore .90914667 86.931793 | \\
\hline 153. $\mid$ & Slovakia $\quad .8394917283 .620987$ | \\
\hline 154. & Slovenia $\quad .87800843 \quad 76.23893 \mid$ \\
\hline 155. & Solomon Islands .5052744225 .097956 \\
\hline 156. $\mid$ & Somalia $\quad \cdot \quad \cdot \mid$ \\
\hline 157. & South Africa $.66294438 \quad 65.260231 \mid$ \\
\hline 158. & South Sudan $\quad .4606151 \quad$. \\
\hline 159. & Spain $\quad .87425739 \quad 83.725952$ \\
\hline 160. & Sri Lanka .7522321951 .745918 | \\
\hline 161. & St Kitts and Nevis $\quad .7469214238 .661663 \mid$ \\
\hline 162. $\mid$ & St Lucia $\quad .72940695 \quad 46.024483$ \\
\hline 163. |S & Tincent and the Grenadines . .7173669940 .146656 \\
\hline 164. & Sudan (2012-) $\quad .47737098 \quad 34.132973$ | \\
\hline 165. & Suriname .71277064 49.666149 | \\
\hline 166. & Swaziland .5301958351 .203434 \\
\hline
\end{tabular}




\begin{tabular}{|c|c|}
\hline 167. & 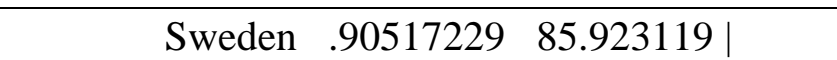 \\
\hline 168. & Switzerland $.92831194 \quad 87.007889$ | \\
\hline 169. & $\begin{array}{lll}\text { Syria } & .6080088 & 48.289585\end{array}$ \\
\hline $170 . \mid$ & Taiwan $\quad$. \\
\hline 171. & Tajikistan .62098193 44.680027| \\
\hline 172. $\mid$ & Tanzania $.5159196936 .080471 \mid$ \\
\hline 173. $\mid$ & Thailand .72436726 70.445587 | \\
\hline 174. $\mid$ & Timor-Leste .60076612 $44.834167 \mid$ \\
\hline 175. $\mid$ & Togo .47331065 51.456238| \\
\hline $176 . \mid$ & Tonga $.7155602 \quad 31.1208 \mid$ \\
\hline $177 . \mid$ & Trinidad and Tobago .77054459 $62.621948 \mid$ \\
\hline $178 . \mid$ & Tunisia $.71984845 \quad 59.097401 \mid$ \\
\hline 179. & Turkey .75895786 $69.952431 \mid$ \\
\hline 180. & Turkmenistan .68202293 37.309826 | \\
\hline 181. & Tuvalu $\quad$. \\
\hline 182. & Uganda .47842792 46.020885 | \\
\hline 183. & Ukraine $.74568254 \quad 70.714745 \mid$ \\
\hline 184. & United Arab Emirates .83322746 75.917915 | \\
\hline 185. & United Kingdom .90209836 81.96537| \\
\hline $186 . \mid$ & United States $.9131397675 .712204 \mid$ \\
\hline 187. $\mid$ & Uruguay $.79028547 \quad 66.148392$ | \\
\hline 188. $\mid$ & Uzbekistan .67224073 41.909775 | \\
\hline 189. & Vanuatu .59202451 41.598053 | \\
\hline 190. $\mid$ & Venezuela .7640674752 .380028 | \\
\hline 191. & Vietnam .66281492 $49.910786 \mid$ \\
\hline 192. & Yemen . $49784687 \quad 45.12286 \mid$ \\
\hline 193. & Zambia $\quad .5802142651 .102558$ | \\
\hline 194. $\mid$ & Zimbabwe $.50078231 \quad 48.514458$ \\
\hline
\end{tabular}


Anexo3 Regresión

Variable dependiente: undp_hdi. Índice de desarrollo humano.

Variable explicativa: dr_ig. Índice de globalización.

$\mathrm{R}^{2}=0,6419$ Lo cual indica que el índice de globalización explica en un 64,19\% el desarrollo humano.

Es estadísticamente significativo teniendo en cuenta que el coeficiente se encuentra en el rango confianza del $95 \%$ (0.0067 y 0.0085$)$.

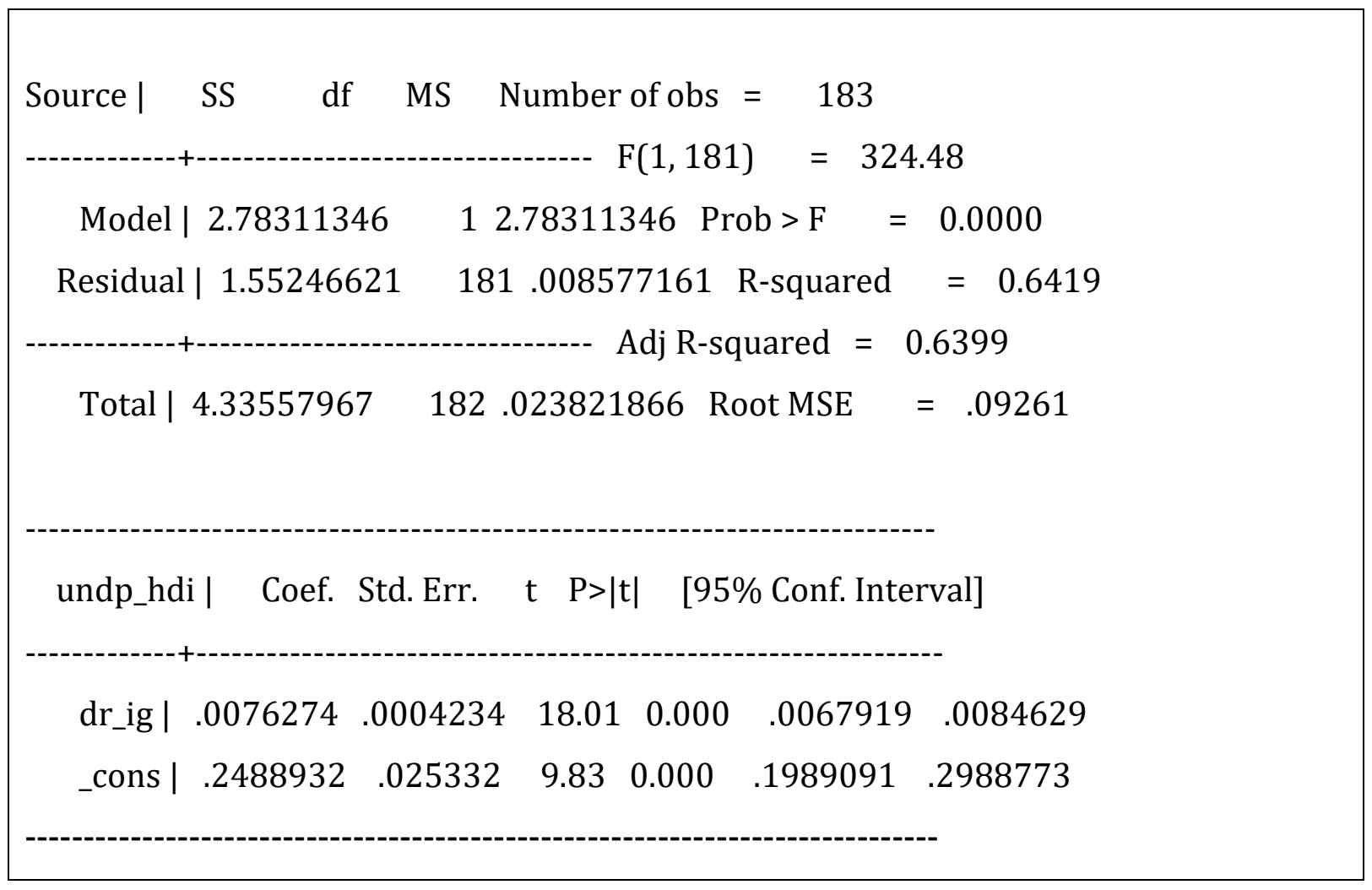




\section{Referencias bibliográficas}

Arrighi, G. (2005) "Estados, mercados y capitalismo, Oriente y Occidente". Anuario AsiaPacífico núm.

1.Recuperado

de http://www.anuarioasiapacifico.es/pdf/2005/032Giovani_Arrighi.pdf el 13 de septiembre de 2017.

Bustelo, G. P. (2007). "¿Chindia o China más India? complementariedad y competencia económicas entre dos gigantes asiáticos". Revista de Economía Mundial. 20: 75-97, 2008. Madrid, ES: B - Sociedad de Economía Mundial.

Baistrocchi, E. (2016). Conferencia "Brexit, Europa y Después". Universidad Torcuato Di Tella, Buenos Aires Argentina, 7 de julio de 2016.

Chomsky, N.(2016).¿Quién domina el mundo?. Barcelona: Ediciones B.

Den Boer, A. y Hudson, V. (30 de abril de 2014)."The security risks of China's abnormal demographics". The Washington Post.. Recuperado de https://www.washingtonpost.com/news/monkey-cage/wp/2014/04/30/thesecurity-risks-of-chinas-abnormal-demographics/?utm term=.1a4dd87c90e8el 20 de diciembre de 2016.

Dhume, S. (30 de diciembre de 2016). "Narendra Modi's year of living dangerously".. American Enterprise Institute. Recuperado de https://www.aei.org/publication/narendra-modis-year-of-living-dangerously/ el 4 de enero de 2017

Friedman, G. (2012). Los próximos cien años. Barcelona: Editorial Destino.

Friedman, T. (2013). La tierra es plana. Madrid: Planeta

Teorell, Jan, Stefan Dahlberg, Sören Holmberg, Bo Rothstein, Anna Khomenko \& Richard Svensson. 2017. The Quality of Government Standard Dataset, version Jan17. University of Gothenburg: The Quality of Government Institute, http://www.qog.pol.gu.se doi:10.18157/QoGStdJan17

Kennedy, Paul. (1987)The Rise and Fall of the Great Powers. Nueva York: Random House.

Krugman, P. (1994). The Myth of Asia's Miracle. Foreign Affairs; Nov/Dec.

Kissinger, H. (2011). On China. Nueva York: Penguin Press.

Kissinger, H. (2016). World Order. Nueva York: Penguin Press.

Lie, E., Tang, M., \& Tan, K. G. (2014). Annual Analysis Of Competitiveness, Simulation Studies And Development Perspective For 34 Greater China Economies: 20002010. Singapur: World Scientific.

Maiza, A., y Bustillo, R. (2016). "Reformas sociales en China: 2016- 2020. Problemas

Del Desarrollo". Revista Latinoamericana de $\quad$ Economía, 46(187), 9-35.

Rajendran, G. Russia and China drive global defence-spending increases in 2015. Recuperado de: www.iiss.org el 14 de marzo de 2017

Malik, M. (2016). Balancing act The China-India-U.S. Triangle. World Affairs. Spring.

Chaturved, S. (2009)“India's Quest for Strategic Space in the 'New' International Order: Locations,(Re)Orientations and Opportunities". p. 15-33 en: Nissam, U. B.India: Economic, Political and Social Issues. Nueva York: Nova Science Publishers, Inc.

Pomeranz, K. (2000). The Great Divergence. Priceton University Press.

Singh, S. (23 de noviembre 2010)"India's Population Time Bomb". The Diplomat. Reuperado de http://thediplomat.com/2010/11/indias-population-time-bomb/3/ el 20 de diciembre de 2016.

Soong, J. (2016). "The Political Economy of the GMS Development Between China and Southeast Asian Countries: Geo-Economy and Strategy Nexus". Chinese Economy, 49(6), 442-455. doi:10.1080/10971475.2016.1207983

UNCTAD. Informe sobre las inversiones en el mundo. ONU. 2014. Recuperado de: http://unctad.org el 20 diciembre de 2016 
World Trade Organization, Trade Profiles 2016. Año 2016. Recuperado de: www.wto.org el 14 de enero de 2017

Scissors, D. Record Chinese Outward Investment in 2016: Don’t Overreact. American Enterprise Institute. Recuperado de: http://www.aei.org/china-global-investment-tracker/ el 14 de diciembre de 2016

The 13th Five-Year Plan for Economic and Social Development of The People's Republic of China (2016-2020) Recuperado de: http://en.ndrc.gov.cn el 22 de julio de 2017

BBC Mundo. Por qué India y Pakistán (potencias nucleares) están de nuevo al borde de la guerra por Cachemira. Recuperado en: http://www.bbc.com/mundo/noticias-internacional$\underline{38086911}$ el 5 de enero de 2017

Base de datos del banco mundial. Consultado en http://databank.worldbank.org

BBC Mundo. Claves de la disputa entre China y Japón por islas estratégicas.

Recuperado de:

http://www.bbc.com/mundo/noticias/2012/09/120914_china_japon_islas_q_and_a_ar el 5 de enero de 2017. 